\title{
A comparison of the use of X-ray and neutron tomographic core scanning techniques for drilling projects: insights from scanning core recovered during the Alpine Fault Deep Fault Drilling Project
}

\author{
Jack N. Williams ${ }^{1}$, Joseph J. Bevitt ${ }^{2}$, and Virginia G. Toy ${ }^{1}$ \\ ${ }^{1}$ Department of Geology, University of Otago, PO Box 56, Dunedin 9054, New Zealand \\ ${ }^{2}$ Australian Centre for Neutron Scattering, Australian Nuclear Science and Technology Organisation, \\ Lucas Heights NSW 2234, Australia \\ Correspondence to: Jack Williams (jack.williams@otago.ac.nz)
}

Received: 20 September 2016 - Revised: 17 December 2016 - Accepted: 16 January 2017 - Published: 31 May 2017

\begin{abstract}
It is now commonplace for non-destructive X-ray computed tomography (CT) scans to be taken of core recovered during a drilling project. However, other forms of tomographic scanning are available, and these may be particularly useful for core that does not possess significant contrasts in density and/or atomic number to which X-rays are sensitive. Here, we compare CT and neutron tomography (NT) scans of $85 \mathrm{~mm}$ diameter core recovered during the first phase of the Deep Fault Drilling Project (DFDP-1) through New Zealand's Alpine Fault. For the instruments used in this study, the highest resolution images were collected in the NT scans. This allows clearer imaging of some rock features than in the CT scans. However, we observe that the highly neutron beam attenuating properties of DFDP-1 core diminish the quality of images towards the interior of the core. A comparison is also made of the suitability of these two scanning techniques for a drilling project. We conclude that CT scanning is far more favourable in most circumstances. Nevertheless, it could still be beneficial to take NT scans over limited intervals of suitable core, where varying contrast is desired.
\end{abstract}

\section{Introduction}

The value of core obtained in drilling projects can be significantly enhanced through the application of non-destructive tomographic scanning techniques. These techniques permit high resolution imaging of the internal structure of the core and allow the identification of features that would not be apparent during visual inspection of the core alone. They may also allow assessment of bulk material properties, such as porosity and permeability (e.g. Grader et al., 2000; Wennberg et al., 2009; Voorn et al., 2015), and act as a historical record of the core once it has been subsampled. For these reasons and others, it is now common to obtain X-ray computed tomographic (CT) scans of core upon its recovery during drilling projects (Rothwell and Rack, 2006; Withjack et al., 2003).
Tomography refers to the cross-sectional imaging of an object through the transmission or reflection of an incident wave penetrating the object from multiple directions. In the case of CT scanning, the internal structure of an object is visualised based on the extent to which it attenuates X-rays. Data like these have demonstrably contributed to the scientific outcomes of drilling projects (e.g. Keren and Kirkpatrick, 2016; Sills, 2013; Withjack et al., 2003). However, the applicability of CT scanning can be limited. For example, if the core does not contain materials that possess significant contrasts in X-ray attenuation, then features within the core will not be observed in the scans. In these cases, other forms of non-destructive tomographic core scanning may be more useful, such as neutron tomography (NT) or nuclear magnetic resonance (NMR) imaging. These techniques use different incident waves from CT scanning, so they are sen- 


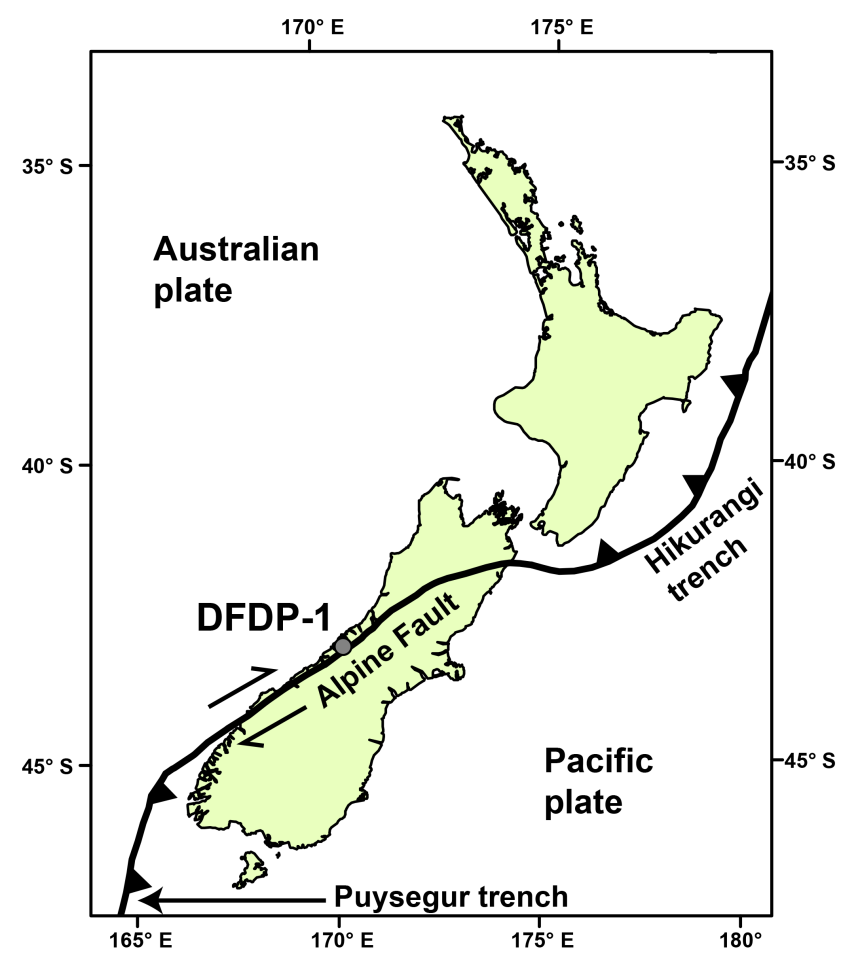

Figure 1. Location of the Alpine Fault and the DFDP-1 boreholes in the context of the Australian-Pacific plate boundary through New Zealand.

sitive to different material properties. Therefore, they can image features that may be poorly resolved in CT images.

In this contribution, we compare and contrast CT and NT scans taken of core collected from phase 1 of the Deep Fault Drilling Project (DFDP-1) through New Zealand's Alpine Fault zone (Fig. 1). Previous assessments have been made of the quality of images derived from CT and NT scanning of geologic materials (Schwarz et al., 2005; Vontobel et al., 2005), including drillcore (Christe et al., 2007). Herein, we provide the first comparison of (1) CT and NT images in samples from an active fault zone and (2) the practicality of these scanning techniques within the constraints of a drilling project.

\section{Experimental set-up of CT and NT scanning of DFDP-1 core}

The Alpine Fault accommodates approximately $70 \%$ of the motion between the Australian and Pacific plates in the South Island of New Zealand (Fig. 1). Several criteria, such as its late interseismic state (Berryman et al., 2012; Sutherland et al., 2007), well-determined Quaternary slip rates (Norris and Cooper, 2001), and the fact that it currently exhumes a suite of deformed rocks with features representative of deformation processes still occurring today, make the Alpine Fault a globally unique target for scientific drilling (Townend et al.,
2009). The Alpine Fault Deep Fault Drilling Project (DFDP, http://alpine.icdp-online.org) was initiated in 2011 with its first phase, resulting in the completion of two vertical boreholes, DFDP-1A and DFDP-1B, drilled to depths of $\sim 100$ and $152 \mathrm{~m}$ respectively. Both holes intercepted the principal slip zone gouges of the Alpine Fault (Sutherland et al., 2012).

Within several weeks of the completion of the DFDP-1 boreholes, $23.2 \mathrm{~m}$ of $\mathrm{PQ}$ (i.e. diameter $85 \mathrm{~mm}$ ) core from DFDP-1A and $50.5 \mathrm{~m}$ from DFDP-1B were CT scanned. In this technique, the attenuation of the $\mathrm{X}$-ray signal is mainly a result of interaction between the X-ray photon and the electrons of an atom's shell (Schwarz et al., 2005; Vontobel et al., 2005). Attenuation reflects the density and the atomic number $(Z)$ of the material it passes through. The raw intensity data are converted linearly to a CT number, which are typically represented visually by a greyscale value (Ketcham and Carlson, 2001).

CT scans were collected at the Oncology Department of Dunedin Hospital, New Zealand. A Philips accolade scanner was operated at $200 \mathrm{~mA}$ and X-ray tube voltage $120 \mathrm{kVp}$, which gives a half value layer of $8.4 \mathrm{~mm}$. The horizontal slice spacing was $1 \mathrm{~mm}$, the field of view was $250 \mathrm{~mm}$, and the image size was $1024 \times 1024$ pixels. This results in a voxel size of $0.244 \times 0.244 \times 1 \mathrm{~mm}$ in the $x, y$, and $z$ directions respectively. To reconstruct the $\mathrm{CT}$ image stack into threedimensional images and two-dimensional slice images of the core, OsiriX imaging software (http://www.osirix-viewer. com/) was used.

NT scans of DFDP-1 core were collected using the thermal neutron tomography instrument, DINGO, at the Australian Centre for Neutron Scattering, Australian Nuclear Sciences and Technology Organisation (ANSTO) in Sydney, Australia (Garbe et al., 2011). Neutrons mainly interact with matter through absorption and scattering with atomic nuclei, so neutron beam attenuation is strongly affected by the presence of light atoms, which present a small cross-sectional area to the neutron flux (Christe et al., 2007). Therefore, NT scans are able to resolve features that contain contrasts in the concentration of light elements, such as hydrogen, boron, and lithium.

The set-up used to scan DFDP-1 core is shown in Fig. 2. Core was wrapped in aluminium foil, which is highly transparent to neutrons. During the scan, the core was rotated around its axis through 180 or $360^{\circ}$ while the neutron beam was passing through it. The scintillation screen of DINGO, and thus the field of view, is $20 \mathrm{~cm} \times 20 \mathrm{~cm}$. The $100 \mu \mathrm{m}$ thick scintillation screen consists of an aluminium sheet, which is coated with a thin layer of the scintillation material $\mathrm{ZnS} / 6 \mathrm{LiF}$ (Garbe et al., 2011). It is possible to translate the sample stage in the $z$ direction (up and down) so that scans are taken in two separate fields of view. In this way, it is possible to scan a core of $<40 \mathrm{~cm}$ in length or two different core samples of $<40 \mathrm{~cm}$ in total length at one time (e.g. Scan 1 , Table 1). In these cases, two separate scans are collected that later require stitching together. 


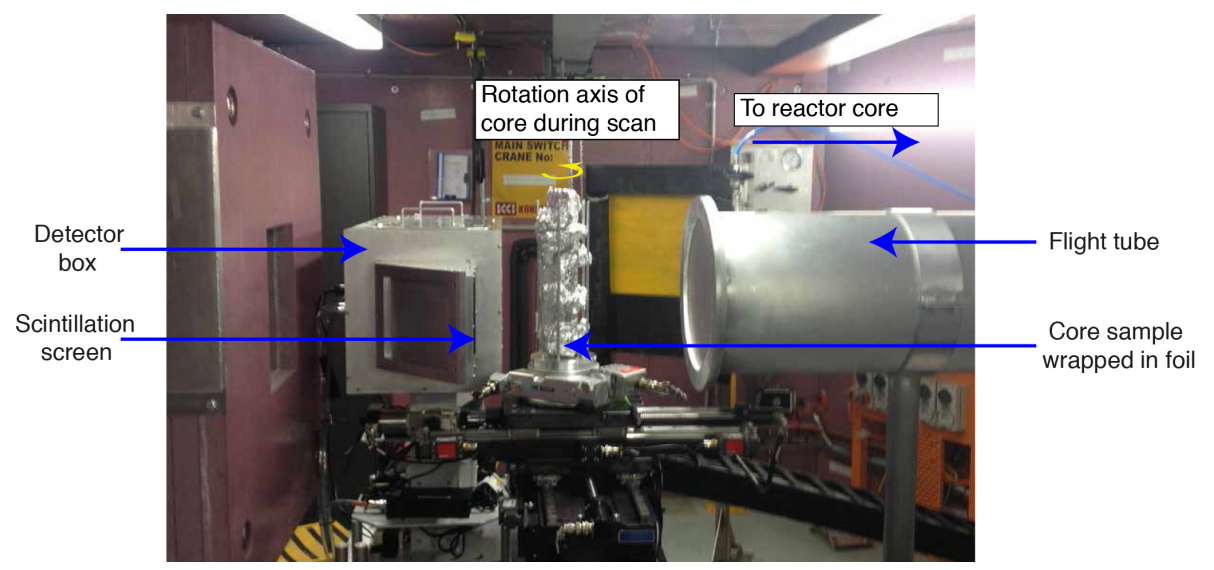

Figure 2. Set-up of DINGO for NT scanning of DFDP-1 core. The field of view is approximately $2.5 \mathrm{~m}$ across.

We selected ten subsamples of DFDP-1 core of $<25 \mathrm{~cm}$ in length. The selection of these samples was based on (1) whether they contained noteworthy fault rock fabrics and (2) ensuring that a range of the lithologies described in DFDP-1 core (Toy et al., 2015) was scanned. Nine samples were whole core and, for comparison, one was split along its length. In 5 days, we were able to perform nine scans (Table 1), which amounted to a total length of $2.26 \mathrm{~m}$ of scanned core.

All core samples were scanned with a low-intensity, low-divergent neutron beam with a collimation ratio of $L / D=1000$, where $L$ is the collimator length and $D$ is the neutron aperture diameter (ASTM, 2013). For comparison, two scans of core were also taken with a highintensity and more divergent beam $(L / D=500)$. When allowing for the collection of reference images of the empty beam, the typical run time for $<20 \mathrm{~cm}$ of core was $\sim 5 \mathrm{~h}$. For scanning intervals of core from 20 to $40 \mathrm{~cm}$, which required the automated height adjustment of the scintillation screen, the run times were $\sim 10 \mathrm{~h}$. The raw image files collected from the scan were reconstructed into an image stack comprising slices perpendicular to the rotation axis using Octopus Reconstruction (https://octopusimaging.eu/octopus/ octopus-reconstruction). In this step, a beam hardening correction was applied to the images. The actual correction applied was chosen subjectively, since noise can be added to images in which a beam hardening correction is too harsh. Image stacks were then viewed using the software Avizo (http://www.fei.com/software/avizo3d/), after the application of Avizo's Non-Local Means smoothing image filter.

\section{CT and NT image comparison}

Broadly speaking, the DFDP-1 cores scanned comprise two types of lithology: ultramylonites (Units 1 and 2 of Toy et al., 2015) and cataclasites (Units 3, 4 and 6 of Toy et al., 2015). Ultramylonites contain a foliation defined by alternating millimetre-centimetre quartzofeldspathic and phyllosilicaterich (biotite, muscovite, and chlorite) layers. Cataclasites are found to contain millimetre-centimetre quartzofeldspathic clasts surrounded by a phyllosilicate matrix. All lithologies are cross-cut by millimetre-centimetre thick clay-enriched fractures, which contain quartz, albite, muscovite, chlorite, calcite, and smectite, that constitute the damage zone of the Alpine Fault (Caine et al., 1996; Schleicher et al., 2015; Toy et al., 2015; Williams et al., 2016).

Figures 3 and 4 present a comparison of CT and NT scans of ultramylonite units and cataclasite units respectively. In addition, we include $180^{\circ}$ of unrolled Geotek images of the same interval of core. Both scanning techniques are capable of imaging the core features described above, in particular clay-enriched fractures. In NT scans, these fractures appear bright white, indicating high neutron attenuation and therefore relatively high concentrations of hydrogen. This may reflect the fact that the clays contain bonded water in their mineralogical structure. Open and partially open fractures were more successfully imaged by CT scanning (Fig. 3c).

The voxel size in NT scans is $0.000870 \mathrm{~mm}^{3}$ ( 3 s.f.), which is $\sim 70$ times smaller than the voxel size of the CT scans $\left(0.0595 \mathrm{~mm}^{3} 3\right.$ s.f. - significant figures). This allows better characterisation of the morphology of the fractures, the identification of some fractures not identified in the CT scans (e.g. Fig. 3b), and more precise imaging of the cataclastic fabric (Fig. 4a). However, we note that industrial CT instruments may permit higher spatial resolution $(100-200 \mu \mathrm{m})$ than the medical CT instrument used in this study (Kyle and Ketcham, 2015; Masschaele et al., 2013). In addition, the resolution of the CT scans will depend on core diameter and density. Therefore, the higher resolution of the NT scans in this study will not necessarily be realised in all cases.

DFDP-1 core was found to be highly neutron attenuating and therefore posed considerable challenges in imaging the centre of the drillcore, even after the application of a beam hardening correction. In Fig. $4 \mathrm{c}$ and d, it can be observed that it is difficult to trace features that are well defined near 
Table 1. Summary of core samples and acquisition parameters for the NT scans performed on DFDP-1 core on the NT instrument DINGO at ANSTO.

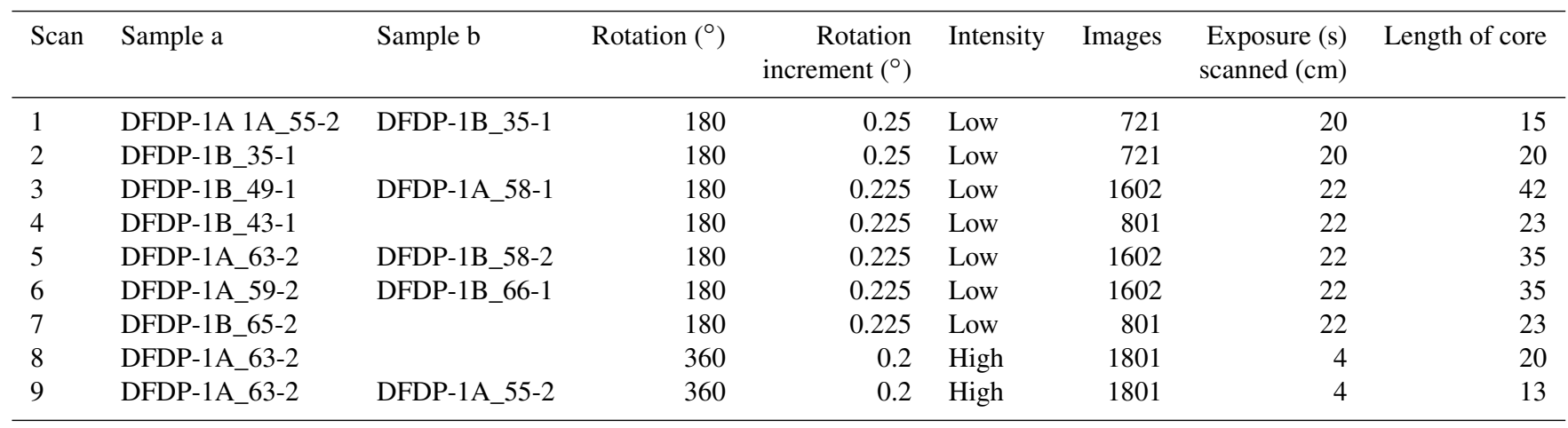

Table 2. A comparison of the practicality of CT and NT scanning in the framework of a drilling project.

\begin{tabular}{|c|c|c|}
\hline & $\mathrm{X}$-ray computed tomography scanning & Neutron tomography scanning \\
\hline (i) Applicability to geologic materials & Broadly applicable to all geological materials & $\begin{array}{l}\text { Not recommended for wet (i.e. H-rich) samples; } \\
\text { Better suited to dry, dense geological materials }\end{array}$ \\
\hline (ii) Availability and portability of scanner & $\begin{array}{l}\text { Widely available at major hospitals and scientific institutions; } \\
\text { Portable, so can be brought onto a drill site or ship }\end{array}$ & Requires neutron source, limited availability \\
\hline (iii) Scanning rate & $12 \mathrm{mh}^{-1}$ & $\sim 50-200 \mathrm{~cm} \mathrm{day}^{-1}$, depending on scanner set-up \\
\hline (iv) Maximum length of core scanned & $\sim 1.5 \mathrm{~m}$ & $40 \mathrm{~cm}$ \\
\hline (v) Resolution & $100-1000 \mu \mathrm{m}$, depending on direction & $\sim 25-200 \mu \mathrm{m}$, independent of direction \\
\hline (vi) Sensitive to & Contrasts in density and atomic number & Presence of hydrogen and other light elements \\
\hline (vii) Penetration & $\begin{array}{l}10-50 \mathrm{~cm} \text {, depending on sample composition, } \\
\text { X-ray energy and desired image quality }\end{array}$ & $10-50 \mathrm{~cm}$, depending on sample composition \\
\hline (viii) Cost, per metre of drillcore & USD $15 / \mathrm{m}^{\mathrm{a}}$ & USD $2640-10560 / \mathrm{m}^{\mathrm{b}}$ \\
\hline
\end{tabular}

a Calculated assuming that it is possible to scan $12 \mathrm{~m}$ of core per hour (i.e. each scan of a $1 \mathrm{~m}$ core section takes 5 min); pricing structure at the Dunedin Hospital Oncology Department.

$\mathrm{b}$ Based on a scanning rate of $50-200 \mathrm{~cm} \mathrm{day}^{-1}$ and the commercial pricing for use of the DINGO facility at ANSTO

(http://www.ansto.gov.au/ResearchHub/Bragg/Users/Requestingbeamtime/CommercialPrices/index.htm).

the outer surface of the core, into its centre. This problem is exemplified in Fig. 5., which shows unrolled images of the CT and NT scans generated using a script in Fiji (https://fiji. sc/). To obtain these, the image stack is loaded in Fiji and a circle is drawn around the core in an axial-perpendicular slice. This is then used to a define a path around which the image is constructed for all slices perpendicular to the core axis. In this way, we can generate circumferential images of the outer surface of the core and also of surfaces within the core interior.

In the case of the NT scans, this shows that it is possible to resolve more features that are closer to the outer surface of the core, where there has been less absorption and scattering of the neutron beam, than in an interior surface of the core (Fig. 5). This result was found regardless of whether the core was scanned using a low- or high-intensity neutron beam. Therefore, the most successful imaging of the interior of highly neutron attenuating core will be acquired in split core samples, such as in Fig. 4a, with a thickness of $3.5 \mathrm{~cm}$.
Similar problems with neutron penetration were also encountered by Christe et al. (2007); however, a correction to account for neutron scattering could mitigate this to an extent (Hassanein et al., 2005, 2006). No such penetration issues were found when CT scanning DFDP-1 core.

\section{Applying CT and NT scanning during drilling projects}

Table 2 outlines a list of criteria that may be applied when deciding which scanning technique to employ during a drilling project. Based on these criteria, CT scanning is more advantageous than NT scanning. For example, whereas CT scanning is suitable for a wide range of geological samples, NT scanning may not be appropriate for wet samples as the high amounts of $\mathrm{H}$ they contain will mean they have strongly neutron attenuating properties (Table 2i). Furthermore, whereas CT scanners are widespread and portable - to the extent that they can be brought onto a drill site or ship (Freifeld et al., 
Geotek core scan

(a)

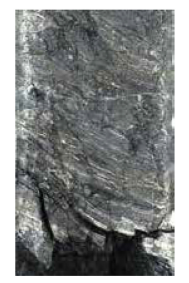

(b)

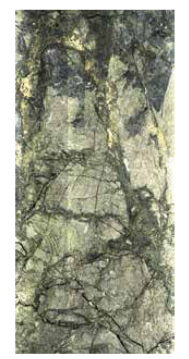

(c)

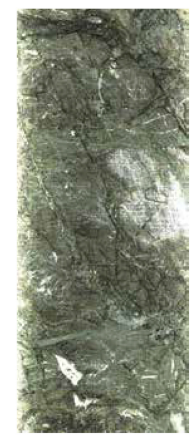

CT scan
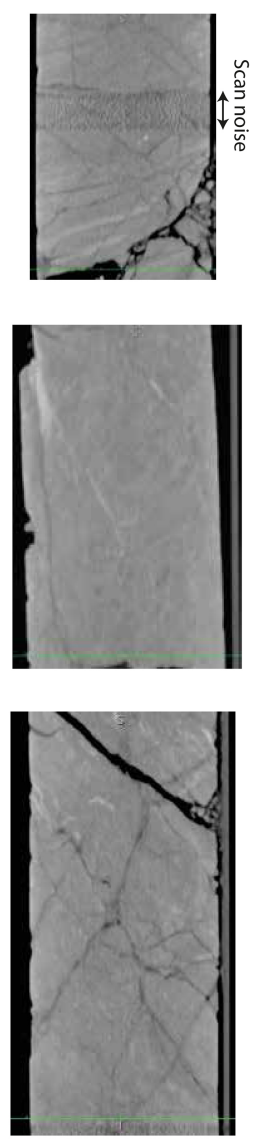
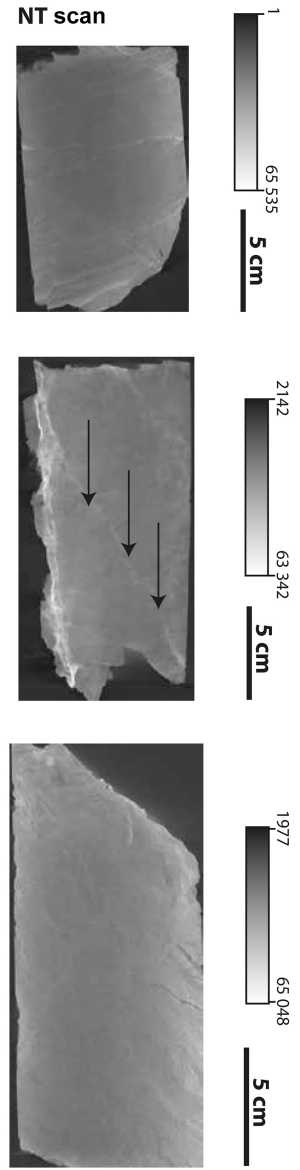

Figure 3. Comparison of $180^{\circ}$ unrolled Geotek images and 2D core axial-parallel CT and NT slice images of DFDP-1 for ultramylonite intervals. For core section intervals (borehole_core run and section_depth interval from the top of the core section in cm) (a) DFDP-1A_55-1_82-95 (depth interval 75.82-75.95 m), (b) DFDP-1B_49-1_35-50 (115.85-116.00m), and (c) DFDP1B_35-1_70-88 (102.57-102.75 m). Arrows in (b) identify a clayenriched fracture in the NT image that is not identified in the CT images. Greyscale refers to NT images, and all CT images have a greyscale of CT 500-4000.

2006) - NT scanners require a neutron source, of which only a handful are available worldwide (Table 2ii).

When designing a core flow plan for a drilling project, it is often critical that the rate of core scanning is equal to or exceeds the rate at which core is recovered. This is in order to prevent the accumulation of unscanned core, which can lead to delays in other aspects of the core flow plan. In this respect, CT scanning is preferable as core can be scanned more rapidly than the rate at which it is recovered (Table 2iii, assuming an average core recovery rate of $1 \mathrm{~m}$ per hour). In CT scanning, the X-ray source and detector can be moved rapidly around the long axis of a fixed sample (Ketcham and Carlson, 2001; Schwarz et al., 2005). Conversely, in the case of NT scanning, the neutron source and detector are fixed

whilst the sample is rotated through 180 or $360^{\circ}$. In addition, once the NT scans have been taken, further processing of the raw sinograms is required to construct the image stack. Moreover, in our experience of scanning DFDP-1 core, it was also necessary that the core be quarantined for 1-2 weeks at the scanning facility before their radiation decayed to safe background levels.

The current set-up of DINGO limits the maximum length of core that can be scanned to $40 \mathrm{~cm}$ (Table 2iv). This limit is imposed by the maximum vertical movement of the sample stage relative to the scintillation screen. In future, it is conceivable that a continuous scan of whole core sections $>40 \mathrm{~cm}$ in length may be carried out on DINGO if core is mounted on a horizontal axis rotation stage (as opposed to the current vertical rotation set-up, Fig. 2) so that core is translated horizontally past the scintillation screen between measurements. In such a set-up, the field of view will still be $20 \mathrm{~cm}$, so the generation of a continuous image stack of the entire core section will require that the individual scans be stitched together.

Given the above considerations, in the framework of a drilling project, CT scanning is more desirable than NT scanning. However, instances exist when it would be desirable to take NT scans, given that they are more sensitive to different material contrasts than CT scans (Table 2vi). We therefore propose the following strategy for scanning core. On site, or immediately after core recovery, all core should be CT scanned. This will provide an excellent "bulk" dataset of the core and, along with visual core descriptions, allow the determination of noteworthy intervals. We advocate that these selected intervals should then be imaged by NT as this allows the identification of features that may not have been resolved during CT scanning. The most successful NT imaging will be performed for core samples that contain localised amounts of hydrogen or other light elements, which are surrounded by only weakly interacting materials, such as in the case of DFDP-1 core. In cases of cores that contain a relatively high amount of strongly neutron attenuating elements, successful imaging can still be achieved if the core is split before NT scanning or if smaller diameter core is collected at the outset.

\section{Conclusions}

We have reviewed the use of X-ray computed tomography (CT) and neutron tomography (NT) to scan core recovered during the first phase of the Deep Fault Drilling Project (DFDP-1) through New Zealand's Alpine Fault. Both scanning techniques successfully imaged millimetre-centimetre core features, such as clay-enriched fractures and cataclasite fabrics. The morphology of these features was more adequately captured by the NT scanning as it is capable of higher resolution imaging than the CT scans; however, because of the highly neutron attenuating properties of DFDP-1 core, 

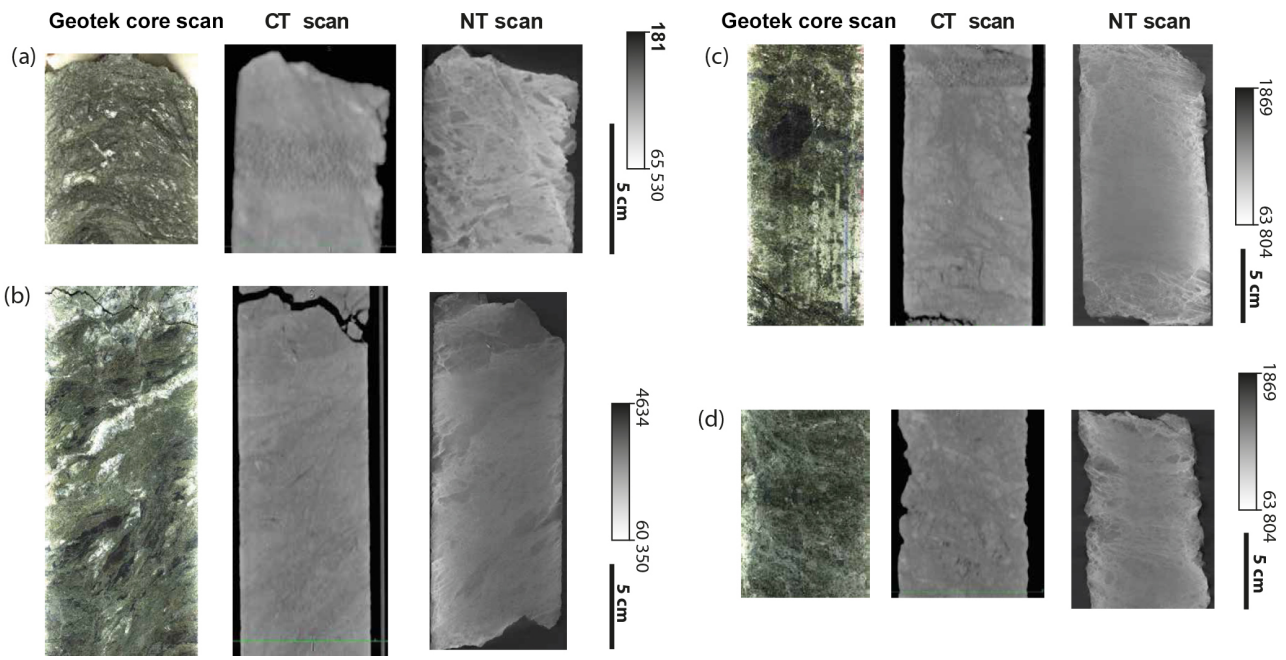

Figure 4. As for Fig. 3, but for cataclasite units. For core section intervals (borehole_core run and section_depth interval from the top of the core section in cm) (a) DFDP-1B_58-2_0-8 (depth interval 127.93-128.01 m), (b) DFDP-1A_63-2_47-70 (86.48-86.71 m), (c) DFDP1A_59-2_8-27 (80.01-80.20 m), and (d) DFDP-1B_66-1_40-53 (138.50-138.63 m). Note that (a) is the split core sample.
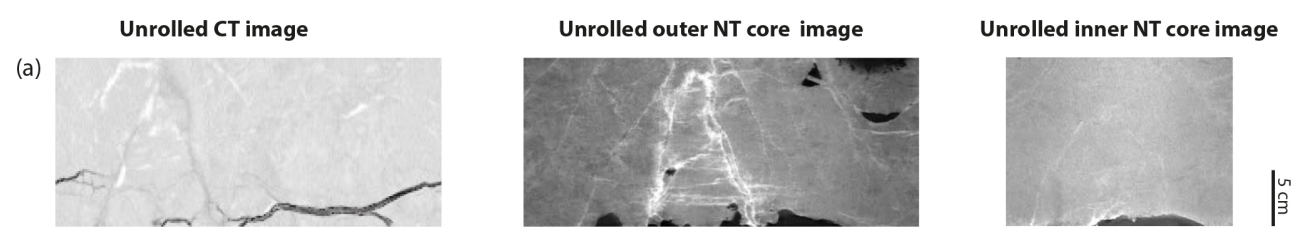

(b)
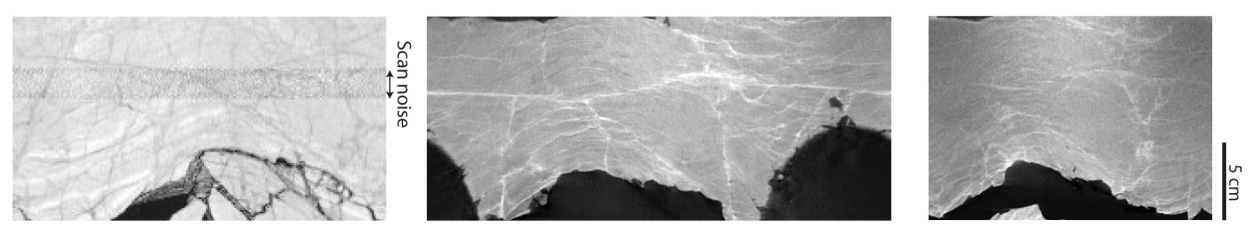

(c)
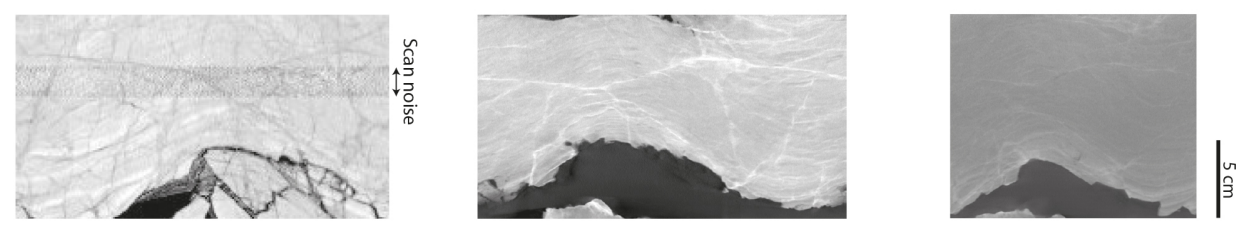

Figure 5. Comparison of unrolled images of core taken from CT and NT scans. Outer and inner core images are constructed from the NT scans to depict the difference in image quality between the outer core surface and the core interior. For core section intervals (borehole_core run and section_depth interval from the top of the core section in cm) (a) DFDP-1B_49-1_35-50 (depth interval 115.85-116.00 m), (b) at low-intensity mode DFDP-1A_55-1_82-95 (75.82-75.95 m), and (c) at high-intensity mode DFDP-1A_55-1_82-95 (75.82-75.95 m).

these features are poorly resolved towards the centre of the core in NT scans.

In the workflow typically encountered during a drilling project, CT scanning offers considerable advantages in terms of scanning rate, availability of scanners, applicability to a wide range of geologic materials, and cost. We thus recommend that this is used to generate a bulk dataset of the 3-D internal structure of the core. Nevertheless, NT scans have the potential to provide a complementary dataset to these $\mathrm{CT}$ scans over limited intervals of core.

\section{Data availability}

Data are available on request from the corresponding author.

Competing interests. The authors declare that they have no conflict of interest.

Acknowledgements. DFDP-1 was funded by the following: GNS Science; Victoria University of Wellington; the University of Otago; the University of Auckland; the University of Canterbury; 
Deutsche Forschungsgemeinschaft and the University of Bremen; Natural Environment Research Council grants NE/J024449/1, $\mathrm{NE} / \mathrm{G} 524160 / 1$ and NE/H012486/1 and the University of Liverpool; and the Marsden Fund of the Royal Society of New Zealand. The International Continental Scientific Drilling Program provided extensive support. The DINGO thermal neutron instrument is supported by the Australian Government's National Collaborative Research Infrastructure \& Strategy (NCRIS) scheme. Steven Mills (University of Otago) provided the script in Fiji to generate unrolled core images. Jack N. Williams was supported by a University of Otago doctoral scholarship. This paper was significantly improved by reviews from Christian Scheffzuek and an anonymous reviewer.

Edited by: J. Behrmann

Reviewed by: C. Scheffzuek and one anonymous referee

\section{References}

ASTM: (American Society for Testing, Materials), E803-91, Standard Test Method for Determining the L/D Ratio of Neutron Radiography Beams, 2013.

Berryman, K. R., Cochran, U. A., Clark, K. J., Biasi, G. P., Langridge, R. M., and Villamor, P.: Major earthquakes occur regularly on an isolated plate boundary fault, Science, 336, 16901693, 2012.

Caine, J. S., Evans, J. P., and Forster, C. B.: Fault zone architecture and permeability structure, Geology, 24, 1025-1028, 1996.

Christe, P., Bernasconi, M., Vontobel, P., Turberg, P., and Parriaux, A.: Three-dimensional petrographical investigations on borehole rock samples: A comparison between X-ray computed- and neutron tomography, Acta Geotech., 2, 269-279, doi:10.1007/s11440-007-0045-9, 2007.

Freifeld, B. M., Kneafsey, T. J., and Rack, F. R.: On-site geological core analysis using a portable X-ray computed tomographic system, Geol. Soc. London, Spec. Publ., 267, 165-178, 2006.

Garbe, U., Randall, T., and Hughes, C.: The new neutron radiography/tomography/imaging station DINGO at OPAL, in Nuclear Instruments and Methods in Physics Research, Sectio En A: Accelerators, Spectrometers, Detectors and Associated Equipment, 651, 42-46, 2011.

Grader, A. S., Balzarini, M., Radaelli, F., Capasso, G., and Pellegrino, A.: Fracture-Matrix Flow: Quantification and Visualization Using X-Ray Computerized Tomography, in: Dynamics of Fluids in Fractured Rock, edited by: Faybishenko, B., Witherspoon, P. A., and Benson, S. M., 157-168, doi:10.1029/GM122p0157, 2000.

Hassanein, R., Lehmann, E., and Vontobel, P.: Methods of scattering corrections for quantitative neutron radiography, in: Nuclear Instruments and Methods in Physics Research, Section A: Accelerators, Spectrometers, Detectors and Associated Equipment, 542, 353-360, 2005.

Hassanein, R., de Beer, F., Kardjilov, N., and Lehmann, E.: Scattering correction algorithm for neutron radiography and tomography tested at facilities with different beam characteristics, Phys. B Condens. Matter, 385-386, 1194-1196, doi:10.1016/j.physb.2006.05.406, 2006.

Keren, T. T. and Kirkpatrick, J. D.: The damage is done: Low fault friction recorded in the damage zone of the shallow Japan
Trench décollement, J. Geophys. Res. Sol. Ea., 121, 3804-3824, doi:10.1002/2015JB012311, 2016.

Ketcham, R. A. and Carlson, W. D.: Acquisition, optimization and interpretation of X-ray computed tomographic imagery: applications to the geosciences, Comput. Geosci., 27, 381-400, available at: http://ac.els-cdn.com/ S0098300400001163/1-s2.0-S0098300400001163-main. pdf?_tid=47f3eb96-5bd4-11e3-86fc-00000aab0f6b\&acdnat= 1386045485_e323788eaa9cc76ba255f3fba7abec66, 2001.

Kyle, J. R. and Ketcham, R. A.: Application of high resolution X-ray computed tomography to mineral deposit origin, evaluation, and processing, Ore Geol. Rev., 65, 821-839, doi:10.1016/j.oregeorev.2014.09.034, 2015.

Masschaele, B., Dierick, M., Van Loo, D., Boone, M. N., Brabant, L., Pauwels, E., Cnudde, V., and Van Hoorebeke, L.: HECTOR: A $240 \mathrm{kV}$ micro-CT setup optimized for research, J. Phys. Conf. Ser., 463, 12012, doi:10.1088/1742-6596/463/1/012012, 2013.

Norris, R. J. and Cooper, A. F.: Late Quaternary slip rates and slip partitioning on the Alpine Fault, New Zealand, J. Struct. Geol., 23, 507-520, 2001.

Rothwell, R. G. and Rack, F. R.: New techniques in sediment core analysis: an introduction, Geol. Soc. London, Spec. Publ., 267, 1-29, 2006.

Schleicher, A. M., Sutherland, R., Townend, J., Toy, V. G., and van der Pluijm, B. A.: Clay mineral formation and fabric development in the DFDP-1B borehole, central Alpine Fault, New Zealand, New Zeal. J. Geol. Geophys., 58, 13-21, 2015.

Schwarz, D., Vontobel, P., Lehmann, E. H., Meyer, C. A., and Bongartz, G.: Neutron Tomography of Internal Structures of Vertebrate Remains?: a Comparison With X-Ray Computed Tomography, Palaeontol. Electron., 8, 11 pp., 2005.

Sills, D. W.: The fabric of clasts, veins and foliations within the actively creeping zones of the San Andreas Fault at SAFOD: implications for deformation processes, 2013.

Sutherland, R., Eberhart-Phillips, D., Harris, R. A., Stern, T., Bevan, J., Ellis, S., Henrys, D., Cox, S., Norris, R. J., Berryman, K. R., Townend, J., Bannister, S., Pettinga, J., Leitner, B., Wallace, L., Little, T. A., Cooper, A. F., Yetton, M., and Stirling, M.: Do great earthquakes occur on the Alpine fault in central South Island, New Zealand?. A continental plate boundary: tectonics at South Island, New Zealand, edited by: Okaya, D., Stern, T., and Davey, F., American Geophysical Union, Washington D.C., 2007.

Sutherland, R., Toy, V. G., Townend, J., Cox, S. C., Eccles, J. D., Faulkner, D. R., Prior, D. J., Norris, R. J., and Mariani, E.: Drilling reveals fluid control on architecture and rupture of the Alpine fault, New Zealand, Geology, 40, 1143-1146, doi:10.1130/G33614.1, 2012.

Townend, J., Sutherland, R., and Toy, V.: Deep Fault Drilling Project - Alpine Fault, New Zealand, Sci. Dril., 8, 75-82, doi:10.2204/iodp.sd.8.12.2009, 2009.

Toy, V. G., Boulton, C. J., Sutherland, R., Townend, J., Norris, R. J., Little, T. A., Prior, D. J., Mariani, E., Faulkner, D., Menzies, C. D., Scott, H., and Carpenter, B. M.: Fault rock lithologies and architecture of the central Alpine fault, New Zealand, revealed by DFDP-1 drilling, Lithosphere, 7, 155-173, doi:10.1130/L395.1, 2015.

Vontobel, P., Lehmann, E., and Carlson, W. D.: Comparison of Xray and neutron tomography investigations of geological materials, IEEE T. Nucl. Sci., 52, 338-341, 2005. 
Voorn, M., Exner, U., Barnhoorn, A., Baud, P., and Reuschlé, T.: Porosity, permeability and 3D fracture network characterisation of dolomite reservoir rock samples, J. Pet. Sci. Eng., 127, 270285, doi:10.1016/j.petrol.2014.12.019, 2015.

Wennberg, O. P., Rennan, L., and Basquet, R.: Computed tomography scan imaging of natural open fractures in a porous rock; geometry and fluid flow, Geophys. Prospect., 57, 239-249, 2009.

Williams, J. N., Toy, V. G., Massiot, C., McNamara, D. D., and Wang, T.: Damaged beyond repair? Characterising the damage zone of a fault late in its interseismic cycle, the Alpine Fault, New Zealand, J. Struct. Geol., 90, 76-94, doi:10.1016/j.jsg.2016.07.006, 2016.
Withjack, E. M., Devier, C., and Michael, G.: The Role of X-Ray Computed Tomography in Core Analysis, Soc. Pet. Eng., SPE Western Regional/AAPG Pacific Section Joint Meeting, 19-24 May, Long Beach, California, doi:10.2118/83467-MS, 2003. 